\title{
Treatment Epoch
}

National Cancer Institute

\section{Source}

National Cancer Institute. Treatment Epoch. NCI Thesaurus. Code C101526.

A period in a clinical study during which subjects receive therapeutic treatment. 